\title{
CORRECTION
}

\section{Correction to: Trauma workload during COVID19 lockdown: an analysis of incidence in 4 million people}

\author{
Alessandro Aprato $^{1} \cdot$ Nathalie Bini $^{1} \cdot$ Silvia Ferro $^{2} \cdot$ Lucia Favella $^{2} \cdot$ Luigi Conforti $^{1} \cdot$ Alessandro Massè $^{1}$ \\ Published online: 22 March 2021 \\ (c) Royal Academy of Medicine in Ireland 2021
}

Correction to: Irish Journal of Medical Science (2021) https://doi.org/10.1007/s11845-021-02548-9

The original article contains an error. In Affiliation 2, "Athens, Georgia, USA" should be change to "Turin, Italy". Author Affiliation should write as follows: ${ }^{2}$ Piedmont Regional Health Center, Turin, Italy.

The original article has been corrected.

The original article can be found online at https://doi.org/10.1007/ s11845-021-02548-9.

\footnotetext{
Alessandro Aprato

ale_aprato@hotmail.com

1 School of Medicine, University of Turin, Turin, Italy

2 Piedmont Regional Health Center, Turin, Italy
} 